\title{
Ensino e uso de língua(s)
}

\author{
Vanessa Fonseca Barbosa ${ }^{1}$ \\ Departamento de Letras Clássicas e Vernáculas, Universidade de São Paulo, São Paulo, SP, Brasil \\ Bernardo Kolling Limberger ${ }^{2}$ \\ Programa de Pós-Graduação em Letras, Universidade Federal de Pelotas, Pelotas, RS, Brasil
}

Helano Ribeiro ${ }^{3}$

Programa de Pós-Graduação em Letras, Universidade Federal de Pelotas, Pelotas, RS, Brasil

\section{Apresentação}

Vivemos um momento histórico marcado por questionamentos a respeito da função do saber científico para o desenvolvimento de nossa sociedade. Nesse contexto, circulam diversas opiniões equivocadas sobre os mais variados temas, as quais se sustentam, muitas vezes, devido à falta de conhecimento e de divulgação necessária da vasta produção científica existente em nosso país que muito tem a contribuir na resolução de problemas sociais.

Para lidar com essa problemática, enfatizamos a importância de espaços como este, que reconheçam e deem voz para que os pesquisadores possam divulgar os resultados de seus trabalhos, considerando também o fato de que a leitura deve ser compreendida como uma prática social que sempre se relaciona com outros textos e outras leituras (KLEIMAN, 2013). Nesse sentido, a Revista Linguagem \& Ensino se caracteriza por ser um desses espaços, sempre em aprimoramento de acordo com as demandas da comunidade acadêmica, dos indexadores e das agências reguladoras dos periódicos (LEFFA, 1998, 2002). Afinal, reconhecemos a relevância de divulgarmos os resultados de pesquisas, por meio da escrita de artigos, tendo em vista que se trata de uma das formas de perpetuação do conhecimento científico que

\footnotetext{
${ }^{1}$ Doutorado em Letras pela Pontifícia Universidade Católica do Rio Grande do Sul, PUCRS (CNPq/CAPES). Pósdoutoranda em Letras no Departamento de Letras Clássicas e Vernáculas da FFLCH/USP. Área: Filologia e Língua Portuguesa (USP/CAPES). Orcid: http://orcid.org/0000-0003-2901-015X

E-mail: vanessafonbar@usp.br

2 Doutorado em Letras/Linguística (PUCRS/CNPq). Professor adjunto da Universidade Federal de Pelotas. Orcid: http://orcid.org/0000-0001-5504-2361

E-mail: limberger.bernardo@gmail.com

3 Doutorado em Teoria Literária (UFSC). Professor da Universidade Federal de Pelotas (UFPEL). Orcid: http://orcid.org/0000-0003-0192-0397

E-mail: hjcribeiro@gmail.com
} 
possibilita um ininterrupto diálogo entre os trabalhos existentes e, assim, permite-nos avançar nas mais variadas áreas do conhecimento.

As práticas discursivas advindas do processo de escrita acadêmica, possibilitam, conforme salientam Bonini e Figueiredo (2010), ao sujeito participar da construção e transformação de sistemas de conhecimento e crença, constituindo-se inclusive enquanto identidade social. Assim, através das publicações, os pesquisadores têm a oportunidade de efetivar esse compromisso de transformação do processo de produção do conhecimento, por meio da disseminação de seus trabalhos à comunidade científica, bem como de contribuir com a construção de um espaço identitário.

Ademais, defendemos que as revistas acadêmicas têm um compromisso social e dever a cumprir a partir de suas publicações, já que "[...] a pesquisa é um modo de construir a vida social, ao tentar entendê-la" (MOITA LOPES, 2006, p. 85). As revistas são, portanto, um dos meios de comunicação responsáveis pela disponibilização de informações confiáveis, baseadas em dados advindos de investigação científica que, antes de serem repassados, são avaliados por leitores experts, competentes e com distinta produção científica nas áreas e temáticas que julgam.

Ancorados nessas compreensões, organizamos este número da Revista Linguagem \& Ensino a partir de uma chamada de artigos atemática. O número reúne trabalhos de cientistas da linguagem que, embasados em diferentes princípios epistemológicos, têm a língua(gem) como seu objeto permanente de estudo, pesquisa e trabalho. Os artigos deste número, juntamente com os números anteriores, refletem a política de multilinguismo nas publicações da revista. Além disso, temos contempladas diversas subáreas da Linguística em interface com a Literatura, Psicologia, Comunicação, Tecnologia e Educação. Dessa forma, os artigos congregados neste número não deixam de considerar a complexidade do uso da linguagem, multifacetada por natureza. Refletindo a tradição da revista desde a sua fundação (LEFFA, 1998), predominam estudos sobre desafios característicos daqueles que se propõem a estudar o ensino de língua(s), o que exige dos pesquisadores "[...] o domínio de uma vasta literatura, frequentemente repleta de discursos, de (in)verdades, de compromissos teóricos, de práticas homogeneizantes que desestabilizam a inquieta natureza humana, sedenta de liberdade e de autonomia" (BOHN, 2013, p. 79).

Neste volume, nossos leitores contarão com doze artigos e duas resenhas, todos aprovados por dois pareceristas do conselho editorial ou ad hoc. No primeiro artigo que compõe o número, intitulado $A$ escrita no ensino fundamental II: uma análise linguística do erro ortográfico à luz dos modelos baseados no uso, Alcione Souza desenvolve sua pesquisa com vistas a averiguar a potencialidade de uma proposta de intervenção pedagógica realizada com alunos do sexto ano de uma escola pública que apresentavam dificuldades fonoortográficas na aprendizagem de português como língua materna. No segundo artigo, denominado Análise dos movimentos oculares durante a leitura de questões matemáticas por alunos de Engenharia que reprovaram em Cálculo Diferencial Integral I, Maria Christo, Ângela 
Klein, Luis de Resende, Romeu Szmoski, Rafael Borges e Dominik Grätz debruçaram-se sob a análise dos movimentos oculares de nove alunos da UTFPR, a fim de investigar o processo de ensino-aprendizagem de leitura desses acadêmicos, o que também auxilia os docentes na compreensão de como ocorre o processamento da leitura dos estudantes. No artigo A prática de análise linguística na BNCC e a perspectiva sociocultural de ensino e aprendizagem: (in)congruências teórico-metodológicas, Rosana Schmitt, Romário Volk e Francieli Pinton estudam as orientações presentes na BNCC sobre a disciplina de Língua Portuguesa, mais especificamente quanto ao segundo ciclo do ensino fundamental (sexto a nono ano) e observam de que modo o eixo Análise Linguística/Semiótica relaciona-se à perspectiva sociocultural de ensino e aprendizagem.

No trabalho $O$ discurso de violência simbólica em interações no Facebook sobre a participação feminina no cenário dos jogos eletrônicos de combate, Graciele Correia volta-se à compreensão da violência de gênero instaurada nos discursos da mídia social analisada, demonstrando-nos as formas em que tal discurso se constitui. Já no estudo Proficiência digital de professores: competências necessárias para ensinar no século XXI, Josiane Cani, além de demonstrar como o docente pode melhor lidar com a tecnologia na atualidade, discute a potencialidade dessa habilidade para o ensino.

Seguindo a linha de pesquisa sobre ensino de línguas e tecnologias, em Zu Verwendung und Potential von Online-Lernprogrammen und Apps: Erfahrungen und Erwartungen von angehenden DaF-Lehrkräften aus Brasilien (Sobre o uso e a potencialidade de programas online e aplicativos: experiências e expectativas de futuros professores de Alemão como Língua Estrangeira (ALE) no Brasil), Paul Voerkel e Ebal Bolacio analisam questionários sobre o uso de plataformas digitais e aplicativos de aprendizagem de alemão por estudantes universitários brasileiros. No trabalho Percepções de alunos de Letras-inglês para as potencialidades pedagógicas das tecnologias digitais, Marcos Araújo avalia o papel das tecnologias na formação de professores, sob o olhar de dois acadêmicos do curso de LetrasInglês de uma universidade federal. $\mathrm{O}$ artigo The use of tasks in the teaching of Portuguese as a Second Language ( $\mathrm{O}$ uso de tarefas no ensino de português como segunda língua), da autoria de Rosane Silveira, discute o processo de design e de adaptação de um conjunto de tarefas elaboradas por alunos-professores durante a realização de um workshop que tinha por foco o ensino de português para estrangeiros.

No artigo Uma proposta pedagógica para o ensino das literaturas dos países de língua portuguesa na China: teoria da estética da recepção em prática, Xueqing Li dialoga sobre a importância da teoria da Estética da Recepção e do Efeito, de Hans Robert Jauss e Wolfgang Iser, para auxiliar professores de literatura de países de Língua Portuguesa na seleção de obras literárias e o trabalho pedagógico com estas a fim de melhor estimular o desenvolvimento da compreensão leitora dos alunos. Já em Consciência fonológica, leitura e compreensão leitora no alemão como língua adicional, Jordana Konrad e Aline Lorandi, por meio de uma pesquisa realizada com 30 crianças brasileiras aprendizes de alemão como língua adicional, discutem a questão da consciência fonológica, verificando o quanto esta, a partir de instruções explícitas, 
pode contribuir com o processamento e a compreensão leitora. E em Desenvolvimento da autonomia na escrita em língua adicional através do feedback por pares: um relato de experiência, Rafael Zaccaron investiga as potencialidades envoltas na inserção de feedbacks em uma atividade escrita elaborada durante uma aula de inglês como língua adicional em um curso extracurricular na Universidade Federal de Santa Catarina. Encerrando os artigos reunidos neste volume está o trabalho Bi/plurilinguismo e inter/transculturalidade no discurso institucional de uma "escola de encontro bicultural", no qual Robson Carapeto-Conceição analisa representações linguísticas presentes em um discurso institucional de uma escola bilíngue espanhol-alemão na Venezuela.

Por fim, estão publicadas as duas resenhas neste número: Lexikalisch-funktionale Grammatik. Eine Einführung am Beispiel des Französischen mit computerlinguistischer Implementierung (Gramática léxico-funcional. Uma introdução baseada na língua francesa com implementação linguístico-computacional), escrita por Tito Romão e Francisco Nogueira; e Vygotsky - A interação no ensino-aprendizagem de línguas, de Neuda Lago.

Esperamos que os textos reunidos neste número possibilitem diálogos e instiguem pesquisadores de diferentes níveis e áreas a aprofundar seus estudos. Agradecemos aos autores pelas interessantes contribuições, aos pareceristas pela avaliação e aos leitores da revista Linguagem \& Ensino pelo interesse. Desejamos a todos uma ótima leitura!

\section{Referências}

BOHN, Hilário. Ensino e aprendizagem de línguas: os atores da sala de aula e a necessidade de rupturas. In: MOITA LOPES, Luiz Paulo (Org.). Linguística Aplicada na Modernidade Recente: Festschrift para Antonieta Celani. São Paulo: Parábola, 2013. p. 79-98.

BONINI, Adair; FIGUEIREDO, Débora de Carvalho. Letramento e escrita acadêmica: uma experiência com o artigo de pesquisa. In: TFOUNI, Leda Verdiani (Org.). Letramento, escrita e leitura: questões contemporâneas. Campinas, SP: Mercado das Letras, 2010.

KLEIMAN, Angela. Oficina de Leitura: teoria e prática. 15. ed. São Paulo: Pontes Editores, 2013. LEFFA, Vilson. Carta do editor. Linguagem \& Ensino, v. 1, n. 2, p. 7-10, 1998.

LEFFA, Vilson. Carta do editor. Linguagem \& Ensino, v. 5, n. 2, p. 7-10, 2002.

MOITA LOPES, Luiz Paulo. Linguística Aplicada e vida contemporânea. In: MOITA LOPES, Luiz Paulo (Org.) Por uma Linguística Aplicada Indisciplinar. São Paulo: Parábola, 2006. p. 85-107. 